\title{
VITA BREVIS, ARS LONGA
}

\author{
Откуда приходят картины и образы \\ В сознанье художника? Вечный вопрос. \\ Кто говорит - из раздумий и споров, \\ Кто говорит - из страданий и слез... \\ Нет! Никакие земные чувства \\ Не вызовут к жизни ни звуков, ни фраз. \\ Это не мы создаем искусство. \\ Это оно сотворяет нас...
}

Homa Kanpu

УДК 78.01

doi: $10.17223 / 26188929 / 7 / 3$

\section{Полина Волкова, Игорь Кочубей}

\section{ИСТОРИЯ ОДНОГО ЗАБЛУЖДЕНИЯ: “SЕNЕСІО" ПАУЛЯ КЛЕЕ}

В статье выстраивается система аргументации, согласно которой вошедший в триптих «Три картины П. Клее» Эдисона Денисова портрет "Senecio" представляет собой портрет философа Сенеки, одновременно выступившего на арене истории в качестве воспитателя Нерона. То обстоятельство, что другое название картины - «Портрет комедианта Сенекио» - уводит искусствоведов от возможности услышать в созданном на основе первоисточника музыкальном портрете современного композитора отзвуки трагической судьбы Учителя, преданного своим учеником, в том числе мучительного вопрошания, почему такое оказывается возможным, ставит авторов перед необходимостью рассмотреть разные точки зрения на запечатленный художником визуальный образ. Настаивая на правомочности видеть в картине «Senecio» духовный облик наставника императора, авторы обращают внимание не только на такие «сигналы текста», которые раскрывают в картине П. Клее тип мыслителя, чья жизнь оборвалась по воле его подопечного (кровавоогненный фон, круглая голова, отмеченная отсутствием ушных раковин и ротового отверстия, красные глаза, вписанные в знак бесконечности, брови, одна из которых нарисована в форме треугольника вершиной вверх - знак мужского активного начала, другая - в форме по- 
лукруга - знак женского пассивного начала), но и на исторический контекст. Имеется в виду самоубийство Сенеки, которое обернулось трагикомедией. Достаточно вспомнить, что, выполняя приказ Нерона, Сенека сначала вскрыл себе вены на руках, затем, чтобы успеть расстаться с жизнью до заката солнца, на ногах, далее принял яд, действие которого также должно было привести к желаемому результату. Однако смерть не наступала и, надеясь ускорить процесс, Сенека просит погрузить свое тело в бассейн с теплой водой. Тем не менее жизнь оставила философа лишь тогда, когда, согласно опять-таки его просьбе, он был перенесен в натопленную баню, где в итоге и задохнулся от паров. Не менее трагикомично выглядит и то, что супруга Сенеки Помпея Паулина, получившая от него благословение на самоубийство и потому вскрывшая себе вместе с ним вены, была спасена по приказу Нерона, впоследствии неся с достоинством свое вдовство.

Ключевые слова: Клее Пауль, «Senecio», портрет, комедиант, Сенека Луций А., смерть, предательство, искусствоведческий анализ, лингвистический анализ.

Осуществляя музыковедческий анализ сочинения Эдисона Денисова «Три картины Пауля Клее» для солирующего альта и группы из пяти инструментов, в числе которых гобой, валторна, вибрафон, фортепиано и контрабас, Е.О. Купровская предлагает следующую характеристику одной из картин художника, вошедшей в обозначенный триптих, - речь идет о картине «Senecio»: «странное лицо с неправильно расположенными глазами, придающими “портрету” зловещее выражение» [8, с. 17]. То обстоятельство, что слово «портрет» искусствовед берет в кавычки, видится весьма странным, поскольку в своем творчестве художник неоднократно обращался к портретному жанру. Как пишет О. А. Киташова, Пауль Клее «...зачастую ставил перед собой цель, подобно которой не встречалось в искусстве портрета ранее. Не забывая <...> периодически изображать различными способами себя и близких ему людей, Клее отличался стремлением создавать портреты несуществующих в действительности персонажей. Отдельные листы и холсты он посвящал образу того, кого никто и никогда не мог видеть прежде, четко следуя при этом желанию подать собственное произведение именно как портрет» [13, с. 52].

Более того, носящая название "Senecio" («Сенекио») картина атрибутируется исключительно с позиции портретного жанра с той лишь оговоркой, что помимо упомянутого названия существует и 
еще одно: «Портрет комедианта Сенекио» [12]. Примечательным в данном контексте оказывается тот факт, что предложенный Е.О. Купровской искусствоведческий анализ обозначенной работы художника стал в некотором роде эталонным, что опознается на уровне используемой уже новым поколением исследователей приведенной выше цитаты. Думается, что авторитетность мнения Е.О. Купровской не подвергается сомнению, в том числе и в силу семейных уз, связывающих композитора и его избранницу.

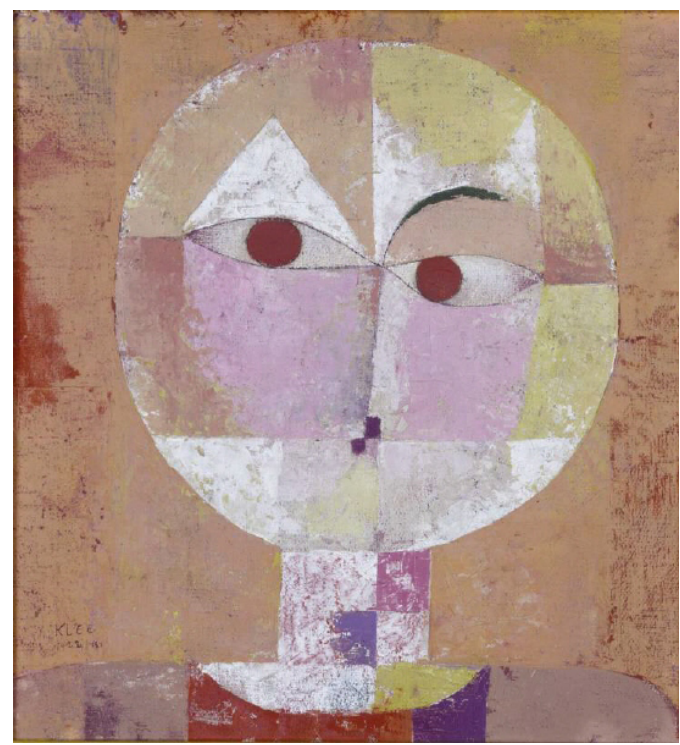

Пауль Клее. "Sепесіо"

Paul Klee. "Senecio"

${ }^{1}$ Оригинальное полотно: холст, масло; размеры 40,3 × 37,4 см; местонахождение: Kunstmuseum Basel (Базельский художественный музей), acces. No. 1569, г. Базель (Швейцарская Конфедерация). Срок действия имущественных авторских прав на данное произведение в РФ истек в 2010 г. Публикуемая в настоящей статье репродукция заимствована из репозитория [18]. (Совершенно необходимо отметить, что в сети Интернет наибольшее распространение получили репродукции, сделанные при другом освещении (с использованием светофильтров?) и / или обработанные (с измененным цветовым тоном и насыщенностью цветов), - характерный пример такого изображения читатель может увидеть на сайте [4].) 
Тем не менее, комментируя точку зрения искусствоведа на картину "Senecio", П.В. Невская высказывает следующую догадку: «Е. Купровская актуализирует содержательно-фактуальную сторону информации интересующего нас текста, пытаясь найти в нем соответствие изображения физическому типу портрета.

Поскольку именно для названного типа симптоматично акцентирование внимания на таких анатомических характеристиках человека, как лицо, руки, тело, ноги, фигура и т.п., искусствовед, поставленный перед очевидностью того факта, что изображенный на картине персонаж отмечен отсутствием не только ротового отверстия, но и ушных раковин, берет лексему “портрет" в кавычки. Более того, отсутствие этих, а также других примет физического портрета, которые позволили бы зрителю получить практически полную информацию о том, какая историческая личность изображена на картине П. Клее, делают для Е. Купровской абсолютно непрозрачным и название картины» [9, с. 10].

Связывая имя портретируемого комедианта с именем философа Сенеки, П.В. Невская считает возможным утверждать, что работа П. Клее представляет собой тип духовного портрета, опираясь на который художник ставит акцент «на жизненном опыте, специфике личности, фокусируя внимание на процессе взаимодействия героя с окружающими его людьми» [Там же]. В качестве сигналов текста, позволяющих зрителю опознать в портретируемом одну из ярчайших личностей эпохи Калигулы и Нерона, П.В. Невская называет:

- отсутствие ушных раковин и ротового отверстия на лице, что является знаком «утратившего веру в слова и не желающего ничего слышать человека» (в скобках заметим, что для изложения своих мыслей Сенека предпочитал письменный жанр, например нравственные письма к Луцилию);

- голова, изображенная в форме идеального круга как знак исключительных мыслительных способностей портретируемого ${ }^{1}$;

${ }^{1}$ Согласно позиции П.В. Невской, то обстоятельство, что музыкальное воплощение визуального образа реализуется, по признанию композитора, посредством «[...] развернутой виртуозной и очень трудной, технически трудной каденцией для solo альта» $[17$, с. 319], видится вполне закономерным. Возможно, сугубо исполнительские сложности выступают здесь аналогом мыслительного процесса, его становления и развертывания в голове философа» [9, c. 11]. 
- разность бровей, когда треугольник коррелирует с мужским началом - Сенека-философ, а полукруг - с женским, поскольку Сенека одновременно предстает и в качестве воспитателя Нерона;

- огненный цвет полотна и красные глаза портретируемого, что в целом звучит в унисон с цветом крови и огня (почеркнем, что кровь здесь становится знаком смерти вскрывшего себе вены Сенеки, а огонь - пожара в Риме, который связывают с именем Нерона) [10].

Обратимся к другим описаниям портрета «Сенекио», почерпнутым в разных источниках:

- «П. Клее. “Сенекио”. Голова мужчины. 1922 год. Холст, наклеенный на дерево, масло. Кунстмузеум, Базель. Вариант названия картины - “Портрет комедианта Сенекио"» [5].

- «на картине “Сенекио" (“Портрет комедианта Сенекио”) схематично изображенное человеческое лицо, "разбитое" на разноцветные четырехугольники; в свою очередь, “лицо” вписано в своеобразную маску - круг, цветовое решение которого напоминает костюм Арлекина. Трактовка полотна неоднозначна, с одной стороны, игра художественной мысли автора, передающего меняющийся образ актера, с другой - взаимосвязь находящихся в вечных переменах искусства, театра и иллюзий творческого человека» [12];

- «...сформированный из геометрических фигур и абстрактных участков цвета портрет изображает, как считается, артиста, выступавшего под псевдонимом Сенецио. Имеющее корень латинского происхождения имя отсылает к слову “senex", что означает “старость" или "старение". Таким образом, мы видим перед собой стареющего персонажа. Ничто в картине, помимо названия, не может сообщить нам об этом, к тому же Клее намеренно не использует какие-либо условные знаки, позволяющие зрителю прочитать произведение привычным - а значит, банальным - образом. Даже в портретах его образность остается строго индивидуальной и базируется исключительно на личном восприятии форм» [13, с. 54].

Получив представление о том, каким образом интересующий нас портрет рассматривается в посвященных творчеству П. Клее сайтах и альбомах, мы считаем необходимым осуществить лингвистический анализ самого названия картины, учитывая ряд обстоятельств. Во-первых, родным языком для художника был немецкий. 
Во-вторых, будучи музыкантом, П. Клее не мог не иметь какого-то, хотя бы и поверхностного, представления об итальянском языке. При этом некоторые названия его картин отмечены обращением к латыни, на что указывают написанная в 1917 г. работа «Ab ovo» (в переводе с латинского «С яйца», т.е. «С самого начала» [13, с. 30] и созданная в 1920 г. картина «Angelus Novus» («Новый ангел»). Наконец, в-третьих, мы отдаем себе отчет в том, что отдельные названия могут нести на себе следы словотворчества художника аналогично тому, как это случилось с картиной "Insula dulcamara" 1 (в переводе с латыни - «Сладко-горький остров») [11, с. 80-81].

Итак, Seneca - это один из когноменов в роде Annaeus (Аннеев); именно представители этого когномена Сенеки наиболее прославились в названном роде: это философ и писатель трагедий Луций Анней Сенека (Lucius Annaeus Seneca, ок. 4 г. до н. э. - 65 г. н. э.), a также происходивший из испанского торгового города Кордубы ритор Анней Сенека (Annaeus Seneca, ок. 54 г. до н. э. - 39 г. н. э.).

В свою очередь, Senecio (по-русски традиционно передающийся как Сенецион) - один из когноменов в роде Геренниев (Herennius) и др., на что указывает фундаментальный латинский словарь Иосифа Ханановича Дворецкого [1, с. 700] со ссылкой на упоминание этого когномена у Публия (или Гая) Корнелия Тацита (Cornelius Tacitus, ок. 55 г. н. э. - 120 г. н. э.). Herennius был римским номеном (родовым именем). Здесь, во-первых, нужно упомянуть Gajus Herennius (Гая Геренния) - персону, которой была посвящена "Rhetorica ad Herennium". Имеется в виду анонимный труд, авторство которого в течение долгого времени приписывалось вначале Цицерону, а затем Корнифицию. Во-вторых, был также упоминаемый Корнелием Тацитом историк Herennius Senecio (Геренний Сенецион), живший, как и сам Тацит, во времена императора Тита Флавия Домициана.

\footnotetext{
${ }^{1}$ Используемое в названии картины сложносоставное слово не существует, однако его образование оказывается возможным путем сложения имени прилагательного “dulcis" - «сладкий» [1, с. 269] (в этом значении - а оно не единственное - слово используют Публий Овидий Назон, Квинт Гораций Флакк и Тит Лукреций Кар) и имени прилагательного “amarus”- «горький» [Там же, с. 51] (в этом значении - а оно, опять же, не единственное - слово встречается у Гая Плиния Секунда (т.е. Плиния Старшего) и Авла Корнелия Цельса).
} 
Есть еще существительное мужского рода "senecio", которым обозначалось (и посейчас обозначается) растение крестовник, но в архаичном своем значении существительное это имело смысл «старик» и происходило от существительного мужского же рода «Senex» («старик, старец» в смысле мужчины в возрасте 45-60 лет или, чаще, старше 60 лет [1, с. 700]. Таким образом, конечные буквосочетания «-са» и «-сіо» бытовали в именах приблизительно в одно и тоже время, что, на наш взгляд, с учетом различительной функции имени $[3,7,15]$ свидетельствует против возможности неустойчивого написания (колебания) имени в этом его месте. Если, давая название своей картине, Пауль Клее и намеревался сделать какой-то намек на знаменитого философа, намек этот вышел весьма мутным и, стало быть, неудачным. Вывод этот видится вполне закономерным при синхроническом подходе к изучению языка, в рамках которого язык предстает как нечто застывшее во времени. Однако справедливости ради необходимо реализовать также и диахронический, т.е. исторический, подход к языку. Возможно, именно подобный опыт даст нам ответ на вопрос, могло ли в разбираемом имени Seneca «-с-»мутировать в «-сі-» в процессе исторического развития латыни в итальянский язык.

В этом плане уместным будет сопоставить то, как подверглось изменению имя Симпликий ${ }^{1}$ (Simplicius), которое носил представитель Афинской школы неоплатонизма Симпликий Киликийский

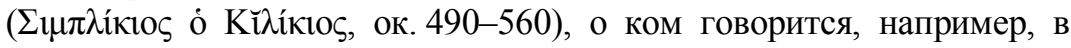
изданной Институтом истории естествознания и техники АН СССР монографии «История естествознания в эпоху эллинизма и Римской империи» И.Д. Рожанского. А вот героя «Диалога о двух главнейших системах мира» (итальянское название «Dialogo sopra i due massimi sistemi del mondo», название на латинском языке «Systema cosmicum», нач. 1632) - главного произведения ${ }^{2}$ Галилео Галилея (Galileo Galilei, 1564 - 1642) - зовут Симпличио (Simplicio) ${ }^{3}$ и никак

${ }^{1}$ Во многих русскоязычных публикациях встречается написание в «латинизированном» виде - Симплиций.

2 Труд этот явился итогом почти тридцатилетней научной работы. Его выход в свет - одна из ключевых вех коперниканской революции в естествознании.

3 Дословно - «простаком», ибо он на протяжении всего диалога занимается «начетничеством» около замшелых (к тому времени) постулатов Аристотеля и Птолемея. 
иначе... Здесь буква «і» (и соответствующий звук) демонстрирует очевидную устойчивость.

Отдавая себе отчет в том, что лингвистический анализ лексемы senecio, послужившей названием картины Пауля Клее, не позволяет безоговорочно принять точку зрения П. В. Невской, выскажем следующее соображение. Наиболее весомым для нас в данном контексте оказывается тот факт, что лексема «senecio», равно как и имя Сенека происходит от одного латинского корня «senectus», т.e. «старый» [2]. Далее указание на портрет комедианта позволяет предположить, что собственная смерть Сенеки, который, идя на самоубийство, выполнял лишь волю Нерона - своего бывшего ученика, сегодня выглядит как некогда старательно разыгранная пьеса. Отчасти именно поэтому окрашенное в трагические тона событие воспринимается сквозь века скорее как фарс или, что то же, - как «непристойное, постыдное, циничное зрелище» [16].

Трагикомичность ситуации заключается, на наш взгляд, в том, что, согласно имеющимся сведениям [6], задолго до двойного самоубийства Сенеки и его супруги Помпеи Паулины философ пытался покончить с собой, узнав о неизлечимом характере своей болезни. Что же касается инициируемого волей Нерона самоубийства, то для семейной пары оно обернулось мучительной погоней за смертью (для него) - Нерон приказал Сенеке осуществить самоубийство до захода солнца - и, одновременно, чудесным спасением (для нее). Знаменательно, что все участники происходящего выступают здесь либо в качестве главных героев этой «пьесы», либо в качестве статистов, либо - зрительской аудитории. При этом сам процесс самоубийства, по сути, разворачивается по законам театра, охватывая четыре акта с прологом и эпилогом ${ }^{1}$. Не случайно исто-

${ }^{1}$ В частности, вся процедура самоубийства, согласно сведениям, полученным от Корнелия Тацита, условно может быть представлена на уровне следующих частей:

Пролог: смертный приговор, вынесенный Нероном Сенеке как участнику заговора против императора.

Aкm 1. Сенека вскрывает вены на руках, однако, поскольку кровь течет медленно, философ проделывает ту же процедуру и с ногами, вскрывая вены на голенях и под коленями (в скобках заметим, что вскрывшую себе вены Паулину по приказу Нерона спасают; впоследствии она с достоинством несет свое вдовство). 
рия смерти Сенеки стала в 80-е годы прошлого века сюжетом для пьесы Петера Хакса «Смерть Сенеки». Как свидетельствует Н.Э. Сейбель, пьеса «...Хакса распадается на две композиционные части: до начала третьего акта и после. Первая половина построена на интермедиальных связях с живописными полотнами и является своего рода приквелом к ним. Вторая - комедия ошибок и недоразумений, возникающих из-за разрушенной ниши, отражающей звук и делающей тайны, сообщенные во внутреннем дворе, достоянием всего дома [14, с. 138]. Думается, что с наибольшей полнотой театральность происходящего раскрывает полотно Жака Луи Давида «Смерть Сенеки».

Еще одним аргументом в пользу того, что на портрете изображен не кто иной, как Сенека,- уже упоминаемый П.В. Невской кроваво-огненный фон, который, в том числе, отвечает ситуации, когда бездыханное тело Сенеки (в полном согласии с его намерением) было подвержено сожжению. Помимо этого, при решении вопроса о портретируемом нельзя обойти вниманием и тот факт, что (со слов Корнелия Тацита) в случае победы участников заговора против Нерона бразды правления планировали передать Сенеке, поскольку Рим не много бы выиграл, не сумев избежать позора, если вместо Нерона - Тацит называет его гитаристом (кифаристом $)^{2}$ - на престол взошел бы комедиант!.. Речь идет о Пизоне, выступавшим в качестве трагика [6]. Другими словами, отталкиваясь от приписываемой У. Шекспиру сентенции «Весь мир театр, а все люди в нем - актеры», можно предположить, что, будучи римлянином и сыном своей эпохи, в какой-то момент и сам Сенека начинает видеться своим потомкам в качестве комедианта.

Aкm 2. Вследствие того что ожидание смерти затягивается, Сенека принимает приготовленный заранее яд, который также не приводит к достижению желаемого.

Акт 3. Намереваясь прекратить мучения, Сенека просит погрузить свое тело в теплую воду бассейна, чтобы повысить интенсивность действия яда.

Aкm 4. Лишь перебравшись в жарко натопленную баню, Сенека встречает свою смерть, задохнувшись от пара.

Эпилог: бездыханное тело Сенеки предают огню.

${ }^{1}$ Рассматриваемый сюжет также встречается на полотнах Якоба ван Оста I, Пауля Рубенса, Кристофо Саволини, Лука Джорджано и др.

${ }^{2}$ Вследствие тяги императора к публичному пению. 
Наконец, самым важным аргументом в пользу высказанной П.В. Невской точки зрения видится следующий момент. Всякое подлинное искусство являет собой опыт сакрального знания, процесс приобщения к которому можно рассматривать в качестве «гимнастики» для упражняющегося в метафизике ума. Соответственно, общезначимый смысл - так называемый этический код, сокрытый как за материальностью холста, так и нотным текстом творений П. Клее и Э. Денисова, не может ограничиваться идеей старения ipse per se (как таковой), тем более что выполненный в абстрактной манере портрет лишь с известной натяжкой можно назвать портретом старика. Думается, что указанием на вполне реальную уместность связать образ портретируемого Паулем Клее с образом Сенеки служат не только отмеченные сигналы текста, а также тот факт, что для художника «мир театра всегда имел значение» $[13, \text { с. } 40]^{1}$, но и «прочитываемая» между строк мысль: каждому, кто однажды возьмет на себя роль учителя, нужно быть готовым к тому, что однажды один из его учеников предаст его... И потому - никогда не спрашивай, в чем причина того, что из века в век все происходит именно так, а не иначе. Прикосновение к этой истине имеет цену лишь тогда, когда, даже зная о невозможности избежать уготованной для Учителя судьбы, мы вновь и вновь несем свет, невзирая на грустное грядущее ${ }^{2}$.

1 «Театральная тематика, - пишет О.А. Киташова, - не редкость в его художественных произведениях... Свой же собственный кукольный театр художник начал делать в качестве подарка сыну Феликсу на девятилетие. Сотворенные из подручных материалов, порой нарочито небрежные и чрезвычайно выразительные, как и остальные образы Клее, куклы настолько понравились мальчику и самому отцу, что первоначальная труппа из восьми надевающихся на руку фигур вскоре разрослась до коллектива из полусотни уникальных персонажей» $[3$, с. 40]. Знаменательно, что впоследствии Феликс стал театральным режиссером. «Мой кукольный театр, - признавался он, - превратил меня в волшебника» $[13$, с. 20].

${ }^{2}$ Косвенным свидетельством того, что подобным образом сформулированный смысл портрета "Senecio" имеет право на существование, будет для нас следующее признание Корнелия Тацита: «Мы полагаем, что перед смертью [Сенека] размышлял и о том, что оказался в общем-то неважным воспитателем» [6]. 


\section{Использованные источники}

1. Дворецкий И.Х. Латинско-русский словарь: Ок. 50000 слов. 3-е изд., испр. М. : Русский язык, 1986. 846 с.

2. Имя Сенека на Имя.Ком. Значение, происхождение, перевод, комментарии, код, рейтинг. URL: imya.com>name/32393 (дата обращения: 12.05.2019).

3. Катханова С.М., Кочубей И.В. Ментальность и грамматика // Современные направления в обучении иностранным языкам в неязыковом вузе : материалы науч.-практ. конф. Краснодар: [Б. и.], 2001. С. 119-120.

4. Клее П. Сенекио: [Репрод. живопис. произведения 1922 г.] // [Артхив соц. сеть художников, коллекционеров и арт-дилеров]. URL: https://artchive.ru/artists/62148 Paul'_Klee/works/247629 Senekio \#show (дата обращения: 27.05.2019).

5. Клее Пауль (Сенекио) // Мегаэнциклопедия Кирилла. URL: megabook.ru〉media/Клее Пауль (Сенекио) (дата обращения: 07.04.2019).

6. Корнелий Тащит П. Сочинения: В двух томах. Том 1. Анналы. Малые произведения. Л. : Наука, 1969. 444 с. (Лит. памятники).

7. Кочубей И.В. К проблеме сущности и динамики движущегося языкового знака // Вторая ежегодная научная конференция Гуманитарного центра КГУКИ. Краснодар - Горячий Ключ (26 июня 2006 г.) Краснодар : [Б. и.], 2006. Вып. 2. C. 54-61.

8. Купровская E.O. Эдисон Денисов и живопись: поиски параллелей. Екатеринбург : [Б. и.], 1996. 24 с.

9. Невская П.В. Визуальность в аспекте художественного портретирования: (На материале картины Пауля Клее «Сенечио») // Культурная жизнь Юга России. Краснодар, 2013. № 2 (49). С. 9-12.

10. Невская П.В. Портрет в пространстве семиотики: вербальное и невербальное : дис. ... д-ра искусствоведения. Саратов, 2013. 430 с.

11. Парч С. Пауль Клее: 1879-1940/ пер. с англ. О.Л. Карловой. Koln : “TASCHEN GmbH” Verlag ; Москва : АРТ-РОДНИК, 2004. С. 80-81.

12. Пауль Клее, «Сенекио» URL: http://jivopis.org/klee-paul--senekio/ (дата обращения: 11.04.2019).

13. Пауль Клее// Лучшие современные художники. М. : Комсомольская правда; Директ-Медиа, 2016. Т. 13. 72 с.

14. Сейбель Н.Э. «Смерть Сенеки» П. Хакса: визуальное и аудиальное // Вестник Челябинского государственного педагогического университета. 2016. № 1. C. $137-142$.

15. Соболевский С.И. Грамматика латинского языка: Теоретическая часть. Морфология и синтаксис. 3-е изд., просмотр. М., 1950. 432 с.

16. Фарс // Толковый словарь Ушакова. URL: dic.akademic.ru (дата обращения: 05.05.2019).

17. Шульгин Д.И. Признание Э. Денисова: По материалам бесед. М. : Композитор, 1998. 465 с.

18. Klee P. Senecio (Baldgreis, Soon to Be Aged): [A graphic file in the *.jpg format] // Wikimedia Commons: [A web site - media file repository making 
available public domain and freely-licensed educational media content]. URL: https://upload.wikimedia.org/wikipedia/commons/3/3f/Paul_Klee\%2C_1922\% 2C_Senecio\%2C_oil_on_gauze $\% 2 \mathrm{C} \_40.3$ \% $\% 3 \% 97 \_37.4$ c cm\%2C_Kunstmuseum Basel.jpg (the date of downloading: 27.05.2019).

\section{Polina S. Volkova, Igor V. Kochubey}

\section{HISTORY OF ONE DELUSION: "SENECIO" OF PAUL KLEE}

Musical almanac of Tomsk State University, 2019, no., pp. 8-20. doi: $10.17223 / 26188929 / 7 / 3$

In the article is built a system of the argumentation according to which the portrait of "Senecio" which entered a triptych "Three pictures of P. Klee" of Edison Denisov represents a portrait of the philosopher Seneca, who at the same time acted on the arena of history as the tutor of Neron. The circumstance that the other name of the picture - "A portrait of the comedian Senecio" takes away art critics from opportunity to hear echoes of a tragic destiny of the Teacher betrayed by his student, including painful asking why this is possible.

All this put authors before need to consider the different points of view for the visual image imprinted by the artist. Insisting on competency to see "Senecio" as a spiritual shape of the mentor of the emperor, authors pay attention not only on such "text signals" which reveal in the painting of P. Klee the type of thinker, whose life was taken at will of his ward (a bloody and fiery background, the round head noted by lack of auricles and mouth opening, a red eyes entered in an infinity sign, eyebrows, one of which is drawn in the form of a triangle apex up - a sign of the man's active beginning, another - in the form of a semicircle - a sign of the female passive beginning), but also on a historical context. The suicide of Seneca turned into a tragicomedy. Enough to remember that, performing the order of Neron, Seneca at first opened to himself veins to manage to leave life before sunset, standing, he took poison which action also had to lead to desirable result. However, the death didn't come and, hoping to accelerate process, Seneca asked to put him into the pool with warm water. Nevertheless, life left the philosopher only when, according to his request, he was transferred to the heated bath where he suffocated from steam.

Tragicomic is also that Seneca's spouse Pompey Paulina after receiving from him blessing on suicide opened her veins together with him, but she was rescued by the order of Neron. Afterwards, she was bearing with dignity the widowhood.

Keywords: "Senecio", portrait, comedian, death, treachery, art criticism analysis, linguistic analysis.

\section{The used sources}

1. Butler I. H. Latin-Russian dictionary. - M.: Publishing house "Russian", 1986. - 846 pages.

2. A name Seneca addressed to. Lump. Value, origin, translation, comments, code, rating [An electronic resource]. - URL: imya.com>name/32393 (date of the address 12.05.2019).

3. Katkhanova S. M., Kochubey I. V. Mentality and grammar//the Modern directions in training in foreign languages in not language higher education institution / 
M-in formations of the Russian Federation, Kuban. the state. un-t. - Krasnodar: [B. and.], 2001. - Page 119-120.

4. P. Senekio's glue: [works of 1922] //[Artkhiv - a social net of artists, collectors and art dealers][An electronic resource]. - URL: https://artchive.ru/artists/62148 Paul' _Klee/works/247629 Senekio\#show (date of the address 27.05.2019).

5. Klee (Senekio)//Megaentsiklopediya Kirill [An electronic resource]. URL: megabook.ru >Media/glue Paul (Senekio) (date of the address 07.04.2019).

6. Cornelius Thucydides P.Compositions: In two volumes. Volume 1. Annals. Small works. - Leningrad: Publishing house "Science", 1969. - 444 pages - (Litas. monuments).

7. Kochubey $I$. $V$. To a problem of essence and dynamics of a moving language sign //the Second annual scientific conference of the KGUKI Humanitarian center: Krasnodar - the Hot Key, on June 26, 2006) / Yuzh. - I Grew. Kulturol. about-in , etc. - Krasnodar: [B. and.], 2006. - Vyp. 2. - Page 54-61.

8. Kuprovskaya E. O. Edison Denisov and painting: searches of parallels. - Yekaterinburg: [B. and.], 1996. -24 pages.

9. Nevsky P. V. Visuality in aspect of art portraiture: (On material of a picture of Paul Senechio Glue) //Cultural life of the South of Russia. - Krasnodar, 2013. - No. 2 (49). - Page 9-12.

10. Nevsky $P$. V. A portrait in semiotics space: verbal and nonverbal: Dis. [...] Dr.s of art criticism. - Saratov, 2013. - 430 pages.

11. Parch S. Paul Klee: 1879-1940 / The translation from English O. L. Karlova. - Koln: "TASCHENGmbH" Verlag; - M.: Publishing house "ART SPRING", 2004 - Page 80-81.

12. Paul Klee, "Senekio" [An electronic resource]. URL: http://jivopis.org/klee-paul - senekio/(date of the address 11.04.2019).

13. Paul Klee//the Best modern artists. Volume 13. - M.: Publishing house "Komsomolskaya Pravda"; Publishing house of "Direkt-media", 2016. - 72 pages.

14. Seybel N. E. "Seneca's death" of P. Haks: visual and audialny//Bulletin of the Chelyabinsk state pedagogical university. -2016. - No. 1. - Page 137-142.

15. Sobolevsky S. I. Grammatika of Latin: Theoretical part. Morphology and syntax. - Prod. the 3rd, seen. - M, 1950. - 432 pages.

16. Farce//Explanatory dictionary of Ushakov [An electronic resource].URL: dic.akademic.ru(date of the address 05.05.2019).

17. Shulgin D. I. E. Denisov's recognition: On materials of conversations. - M.: Publishing house "Composer", 1998. - 465 pages.

18. Klee P. Senecio (Baldgreis, Soon to Be Aged): [A graphic file in the *.jpg format]//Wikimedia Commons : [A web site - media file repository making available public domain and freely-licensed educational media content] [Electronic resource]. - URL: https://upload.wikimedia.org/wikipedia/commons/3/3f/Paul Klee\%2C_1922\%2C_Senecio\%2C_oil_on_gauze $\% 2$ C_40.3_\%C3\%97_37.4_cm\% $\%$ C_Kunstmuseum_Basel.jpg (date of downloading 27.05.2019). 